\title{
DA GESTÃO AMBIENTAL À EDUCAÇÃO AMBIENTAL: AS DIMENSÕES SUBJETIVA E INTERSUBJETIVA NAS PRÁTICAS DE EDUCAÇÃO AMBIENTAL
}

\author{
Daniel Fonseca de Andrade ${ }^{1}$ \\ Marcos Sorrentino ${ }^{2}$
}

\begin{abstract}
Resumo: O objetivo deste artigo é demonstrar que os objetivos dos processos de educação ambiental, diferentemente daqueles das práticas de gestão ambiental, devem se encontrar nas dimensões subjetiva e intersubjetiva da vida, e não na objetiva. Para desenvolver tal argumento, discorre sobre a formação do pensamento na era moderna e sua consequente objetificação, que relegou a subjetividade e a intersubjetividade a um segundo patamar de importância na compreensão sobre a realidade. Em um segundo momento, o artigo trata das limitações do objetivismo e a emergência da complexidade, que propõe uma nova lógica para se olhar e compreender o mundo e os fenômenos. As implicações dessas duas correntes de pensamento para a educação ambiental são, então, analisadas. Por fim, o artigo sugere cinco conceitos - identidade, comunidade, felicidade, diálogo e potência de agir - considerados como boas portas de entrada para o alcance das realidades subjetiva e intersubjetiva por práticas de educação ambiental.
\end{abstract}

Palavras-chave: subjetividade, intersubjetividade, ações ambientais.

\section{FROM ENVIRONMENTAL MANAGEMENT TO ENVIRONMENTAL EDUCATION: SUBJECTIVE AND INTERSUBJECTIVE DIMENSIONS IN ENVIRONMENTAL EDUCATION PRACTICES}

Abstract: The objective of this paper is to demonstrate that the objectives of environmental education processes, differently from those of environmental management, must be placed within the subjective and intersubjective dimensions of life, not in the objective one. To unpack such argument, the paper makes an account of the formation of modern thought and its consequent objectification, which relegated subjectivity and intersubjectivity to a second level of importance in the understanding of reality. Secondly, the paper deals with the limitations of objectivism and the emergence of complexity, which puts forth a new logic to look at and comprehend the world and its phenomena. The implications of both trends for environmental education are then analyzed. Finally, this paper suggests five concepts - identity, community, happiness, dialogue, and power of acting - considered as good entry points to reach subjective and intersubjective realities by environmental education practices.

Keywords: subjectivity, intersubjectivity, environmental actions.

\footnotetext{
${ }^{1}$ Mestre em Ciência Ambiental, Doutorando em Ciência Ambiental pelo Programa de Pós-Graduação em Ciência Ambiental - PROCAM - da Universidade de São Paulo (USP), Ribeirão Preto, Brasil, dfa@usp.br

${ }^{2}$ Professor Doutor do Departamento de Ciências Florestais da ESALQ/USP, Piracicaba, Brasil, sorrentino.ea@gmail.com
} 


\section{DE LA GESTIÓN AMBIENTAL A LA EDUCACIÓN AMBIENTAL: LAS DIMENSIONES SUBJETIVA E INTERSUBJETIVA EN LAS PRÁCTICAS DE EDUCACIÓN AMBIENTAL}

Resumen: El objetivo de este artículo es demostrar que los objetivos de los procesos de educación ambiental, diferentemente de aquellos de las prácticas de gestión ambiental, deben encontrarse en las dimensiones subjetiva e intersubjetiva de la vida, y no en la objetiva. Para desarrollar tal argumento, discurre sobre la formación del pensamiento en la era moderna y su consecuente objetificación, que relegó la subjetividad y la intersubjetividad a un segundo plano de importancia en la comprensión sobre la realidad. En un segundo momento, el artículo trata las limitaciones del objetivismo y la emergencia de la complejidad, que propone una nueva lógica para ver y comprender el mundo y los fenómenos. Entonces las implicaciones de estas dos corrientes de pensamiento para la educación ambiental se analizan. Por fin, el artículo sugiere cinco conceptos - identidad, comunidad, felicidad, diálogo y potencia de actuar - considerados como buenas puertas de entrada para el alcance de las realidades subjetiva e intersubjetiva por prácticas de educación ambiental.

Palabras clave: subjetividad, intersubjetividad, acciones ambientales

\section{Introdução}

Vivemos em um mundo onde a forma como pensamos e organizamos mentalmente o funcionamento da realidade está literalmente definida pelo legado deixado por René Descartes, matemático e filósofo francês do século XVII (GREIG; PIKE; SELBY, 1989). Descartes propôs um novo sistema do pensamento que se tornou influente no mundo ocidental a ponto de o autor ser considerado o pai da filosofia moderna (CAPRA, 1999).

Esse sistema de pensamento está delineado na sua obra "Discurso do Método", na qual definiu quatro preceitos que se tornaram a base da ciência moderna clássica:

O primeiro era o de nunca aceitar algo como verdadeiro que eu não conhecesse claramente como tal [...] e de nada fazer constar de meus juízos que não se apresentasse tão clara e distintamente a meu espírito que eu não tivesse motivo algum de duvidar dele. O segundo, o de repartir cada uma das dificuldades que eu analisasse em tantas parcelas quantas fossem possíveis e necessárias a fim de melhor solucioná-las. O terceiro, o de conduzir por ordem meus pensamentos, iniciando pelos objetos mais simples e mais fáceis de conhecer, para elevar-me, pouco a pouco [...] até o conhecimento dos mais compostos. E o último, o de efetuar em toda parte relações metódicas tão completas e revisões tão gerais nas quais eu tivesse a certeza de nada omitir. (DESCARTES, s.d., p. 6-7).

Tais preceitos, no entanto, assentaram-se sobre um princípio fundamental, que o autor considerou o primeiro da filosofia que procurava:

[...] porém, por desejar então dedicar-me apenas [à] pesquisa da verdade, achei que deveria agir exatamente ao contrário, e rejeitar como totalmente falso tudo aquilo em que pudesse supor a menor dúvida, com o intuito de ver se, depois disso, não restaria algo em meu crédito que fosse completamente incontestável. Ao considerar que os nossos sentidos às vezes nos enganam, quis presumir que não existia nada que fosse tal como eles nos fazem imaginar [...] Porém, logo em seguida, percebi que, ao mesmo tempo que eu queria pensar que tudo era 
falso, fazia[-]se necessário que eu, que pensava, fosse alguma coisa. E, ao notar que esta verdade: eu penso, logo existo, era tão sólida e tão correta que as mais extravagantes suposições dos céticos não seriam capazes de lhe causar abalo, julguei que podia considerá-la, sem escrúpulo algum, o primeiro princípio da filosofia que eu procurava. (DESCARTES, s.d., p. 11).

É importante que se contextualize que a priorização da racionalidade científica em Descartes ocorreu diante da necessidade de se emancipar a ciência dos poderes mitológicos e religiosos e também do conhecimento filosófico e subjetivo, predominantes na época (MORIN, 2001; NICOLESCU, 1999). Para Habermas (1995, p. 175), essa emancipação significou o "desencantamento do mundo", ou seja, um processo pelo qual a unidade do pensamento tradicional foi desmembrada em três esferas culturais de valor, a objetiva, a subjetiva e a intersubjetiva, com valorização da primeira e desvalorização das demais.

Consequentemente a esse processo, a objetividade da realidade passa a ser buscada por meio da fragmentação do pensamento, do uso de uma linguagem objetiva (a matemática) e do distanciamento entre sujeito e objeto, que trariam a garantia da localização da verdade inconteste saneada de qualquer tipo de contaminação (MORIN, 2001).

Em linhas gerais, os princípios nascentes de pensamento consideravam a realidade como formada por conjuntos de unidades separadas, indivisíveis e imutáveis, que existem independentemente em diferentes regiões do espaço e do tempo e interagem de uma forma que não traz mudanças a suas naturezas essenciais (BOHM, 1995). Por isso, considera-se que o mundo de Descartes é um mundo mecânico, como engrenagens de uma máquina (BOHM, 1995, 1999; CAPRA, 1999).

Como existe uma relação direta e "muito profunda" entre como o conhecimento e o pensamento são organizados e como a sociedade é organizada (MORIN, 2007, p. 79), é possível que se reconheçam as aplicações práticas do pensamento cartesiano em qualquer instância das sociedades ocidentais: na gestão dos países, estados e cidades; na organização das empresas; na maneira como vemos e nos relacionamos com o corpo e com a natureza; na forma como os currículos escolares são formatados etc.

No século XIX o absolutismo da ciência clássica começou a experimentar os seus próprios limites. O surgimento de campos de pesquisa (eletrodinâmica, termodinâmica, cosmologia e a teoria da evolução) e também a percepção de fatos e teorias que não poderiam ser explicados ou formulados a partir de seus pressupostos começaram a minar seus alicerces (CAPRA, 1999). Mais tarde, a teoria da relatividade e a noção de campos contínuos de Einstein colocaram a necessidade de se questionar a ordem mecânica da realidade (BOHM, 1995). A crítica trazida por Einstein foi posteriormente complementada pela mecânica quântica. Apesar das diferenças, essas teorias, da relatividade e quântica, compartilhavam um pressuposto: o de que a totalidade (a realidade) é indivisível (IBID).

As implicações dessa mudança são várias e partem da nova racionalidade de que, se a realidade é indivisível, todos os seus componentes são conectados em algum momento, o que impede a possibilidade de existência de algo objetivo, a verdade pura, clara e distinta de Descartes. Consequentemente, emerge a noção de que o pensamento produzido a partir da realidade "objetiva" não reflete a realidade em si, mas uma interpretação da realidade (MORIN, 2007), que se dá a partir das "lentes" de quem olha, as quais por sua vez são determinadas por seus repertórios teóricos, técnicos, ideológicos, entre outros (BOHM, 1995, 1999).

Para a educação ambiental, a questão acima é fundamental. Nascidos em um universo mental cartesiano, que carregamos e reproduzimos, são grandes as chances de que desenvolvamos práticas de EA que respondam única e exclusivamente às questões "objetivas" do mundo em que vivemos, aquelas que são percebidas pelos nossos cinco sentidos e são passíveis 
de mensuração. Com isso, privilegiam-se as ações que lidam diretamente com as questões explícitas e visíveis do meio ambiente, em geral seus problemas e as resoluções destes.

Nesse contexto, o presente trabalho visa a demonstrar que os objetivos dos processos de educação ambiental, diferentemente daqueles das práticas de gestão ambiental, devem se encontrar nas dimensões subjetiva e intersubjetiva da vida, e não na objetiva. Considera-se aqui que há uma confusão entre os princípios e objetivos atribuídos à educação ambiental com aqueles relacionados à gestão ambiental. Ao final, o texto sugere cinco conceitos que podem ser utilizados como caminhos por práticas que desejem alcançar as duas primeiras dimensões: identidade, comunidade, diálogo, felicidade e potência de agir.

\section{Pela hipercomplexidade pedagógica da educação ambiental}

Em projetos, programas e ações de educação ambiental desenvolvidos com educadores, educadoras e educandos é comum a emergência da questão "lixo", ou ainda da necessidade de se implantar a coleta seletiva de materiais recicláveis nas escolas (ou em outros lugares). Analisandose a questão a partir da lente cartesiana e objetiva, descrita nos parágrafos anteriores, conclui-se que o problema diagnosticado é, primeiro, o "lixo" em si, que é verificável (e mensurável e categorizável) e que precisa ser destinado "corretamente"; e segundo, as pessoas, que precisam "aprender" a, por exemplo, separá-lo por tipos de materiais.

Não se deseja aqui insinuar que a questão dos resíduos não é importante, que seu tratamento apropriado não deve ser incentivado ou ainda que o tema não apresenta potencial pedagógico. Mas práticas de gestão ambiental, muito comumente incentivadas em várias localidades como práticas de educação ambiental, apesar de compartilharem aspectos com as últimas, diferem sobremaneira em princípios e objetivos.

Tachizawa (2008) demonstra em seu trabalho que os objetivos principais da gestão ambiental giram em torno da resolução de problemas ambientais e ecológicos, problemas esses concretos e identificáveis, cujas soluções se dão, em grande parte, pela implantação de medidas técnicas ou procedimentais. A iniciativa da coleta seletiva de materiais recicláveis, conforme comentado, é um exemplo típico de ação de gestão ambiental com foco em uma questão objetiva, o lixo.

É em inspirações empresariais do tipo que muitas experiências de educação ambiental vão se alimentar para construir suas próprias práticas. Assim, tornaram-se comuns atividades de coleta de embalagens nas escolas, por exemplo, ou até a decisão de transformar uma escola em um ponto de coleta de materiais recicláveis para todos os seus alunos e, às vezes, até para a comunidade circundante.

Um exemplo de atividade do tipo é descrito por Felix (2007) em uma escola municipal do estado de São Paulo. Em seu texto, a autora justifica que, "por ser o lixo um dos maiores problemas que afetam o meio e ambiente [...]” (FELIX, 2007, p. 60), o projeto foi implantado, com o objetivo de "melhorar o manejo dos resíduos escolares e domiciliares, esclarecer os educandos e os moradores sobre os problemas gerados pelo lixo que não recebe tratamento e acondicionamento correto, as possíveis consequências ao meio ambiente e à saúde pública e, principalmente, provocar mudanças adequadas para a melhoria da qualidade de vida da população, assim como diminuir os impactos ambientais negativos decorrentes da geração de lixo" (FELIX, 2007, p. 60).

Outros projetos de educação ambiental, realizados principalmente em escolas públicas, são estimulados pelo apoio de empresas ou grupos que fazem campanhas de coleta de embalagens nessas instituições.

Nesses casos, tais empresas em geral focam exclusivamente as embalagens de seus produtos, como pode ser visto em Nascimento (2010), cujo projeto demostrado se concentra em 
bebidas, e também em outras iniciativas ${ }^{3}$. Apesar de diferentes fins, a lógica em todos eles é muito parecida: envolver a comunidade escolar na coleta e destinação "correta" de tais embalagens em troca de algum tipo de prêmio.

É nesse momento que se deve levantar o questionamento se este deve ser o papel da educação ambiental na escola ou em qualquer outro âmbito: limitar-se a fazer gestão de problemas ambientais. Em última instância, promover processos nos quais a escola (ou outra instituição) toma o lugar de outros atores (públicos ou privados) que, nesse caso, já fazem a coleta de resíduos e, muitas vezes, até a de materiais recicláveis.

Neste trabalho, defende-se que não. O papel da educação ambiental é reconhecer e extrair, dessas e de outras ações do cotidiano, a "hipercomplexidade" (CAMBI, 1999, p. 598) do campo pedagógico e, na prática, ir além da resolução de problemas ambientais para incluir os aspectos políticos, filosóficos e científicos relacionados a eles. Nesse contexto, focar ações educativas exclusivamente nos aspectos técnicos objetivos, em grande parte, apequena as práticas diante de seus potenciais e desvia a atenção dos educadores e educandos de vários outros aspectos tão ou mais importantes do que eles.

Portanto, uma instituição que não é gestora ambiental por função não deve querer sê-lo. Muitos projetos escolares de gestão/educação ambiental são descontinuados porque se descobre, depois de iniciados, que a instituição não possui os recursos necessários (tempo, materiais, pessoal, conhecimento etc.) para mantê-los. Também constatam que são muito mais complexos e demandam mais atenção do que se esperava inicialmente. Dependendo da natureza da iniciativa, o projeto acaba ganhando uma dimensão desproporcional à capacidade de ação da instituição. Pode se tornar um grande fardo cujas responsabilidades recaem sobre alguns poucos, que, desanimados pela dificuldade e pelo volume das ações operacionais diárias - que tomam o lugar de qualquer fazer pedagógico -, terminam a iniciativa.

Assim, a função primordial da escola não é gerenciar os resíduos gerados por ela e menos ainda os da comunidade. Não é compostar matéria orgânica, fazer uma horta e produzir verduras. Ela pode e deve desenvolver tais práticas, mas elas só terão real sentido em uma instituição educadora se ela for capaz de extrair do lixo, da coleta seletiva, da composteira ou da horta questões pedagógicas para então transformá-las em práticas. Quais são as questões políticas, filosóficas e científicas que esses e outros temas ambientais levantam e como a lida com eles pode criar práticas pedagógicas? Como um tema objetivo e técnico pode propiciar desafio de senso crítico e reflexão? Esses são exemplos de questões que se esperam para a real transformação desses e de outros temas em práticas pedagógicas.

Essa é verdadeiramente a vocação da educação e deveria ser o centro de suas práticas. Isso demanda, no entanto, para cada uma das atividades, um planejamento, um projeto pedagógico que esclareça as dimensões de aprendizado propiciadas por cada uma.

A visão complexa de mundo reconhece as limitações das abordagens "objetivas" e considera que por trás de uma ação (objetiva) há sempre um significado (subjetivo) construído em um mundo coletivo (intersubjetivo). Apesar de invisíveis, tais dimensões são também partes componentes da realidade (MINAYO, 2008) e são fundamentais para a compreensão dessa mesma realidade. Como nossas ações decorrem de nossos pensamentos (BOHM, 2005), são eles o objeto da prática educativa. Assim, reconhecer a subjetividade e a intersubjetividade e incluí-las

\footnotetext{
${ }^{3}$ Um exemplo de projeto do tipo é o Terracycle (http://www.terracycle.com.br/pt-Br/), que estimula a formação de brigadas, inclusive nas escolas, para a coleta específica de embalagens de bombons e salgadinhos. Outros projetos parecidos já existiram e foram descontinuados, como o de coleta de cadernos usados para reciclagem por uma rede de lojas do ramo. Outros são sazonais. A existência desses e de outros projetos em parceria com empresas gera uma efervescência em escolas e professores diante das recompensas e do apoio de infraestrutura oferecidos, que os levam a adotá-los. Muitas vezes, como mostra Bagnolo (2012), tais parcerias se dão dentro dos termos empresariais, que são instrumentais e adestradores, mas que as escolas reproduzem mecânica e acriticamente, por falta de preparo.
} 
no fazer pedagógico significa ampliar o escopo da prática e valorizar aspectos negligenciados em outras circunstâncias.

Tassara e Ardans (2005) indicam que o processo educativo é um constante ato de desvelamento e desvendamento. Desvelar significa tirar o véu que impede o vislumbre nítido do objeto observado, o mundo. Esse véu é tecido por todos aqueles fatores que formam as "lentes" que pautam nossa compreensão da realidade. O desvelamento é, portanto, uma melhor capacidade de perceber esses fatores indutores e, assim, de trazer mais nitidez àquilo outrora obstruído completa ou parcialmente por eles.

O desvelamento do objeto remete a um maior contato não só com os conteúdos do pensamento (com o que pensamos) mas também com o que está por trás desses conteúdos, por que são formados da maneira como são e caminham da forma que caminham (por que pensamos como pensamos, quais as influências que nos levam a pensar como pensamos, quais as consequências de tais pensamentos para as nossas ações etc.) (BOHM, 1995). Assim, o desvelamento dos objetos leva ao desvendamento dos sujeitos, ou seja, à percepção de si como sujeito histórico, mais consciente de sua própria identidade e, portanto, mais capaz de escolhas e adesões intencionais e mais resistente à imposição de símbolos e narrativas homogeneizantes (TASSARA; ARDANS, 2005).

Trazendo esses aspectos para o exemplo da reciclagem, o processo educativo deveria ter foco em questões essenciais, não ligadas diretamente ao ato de reciclar o lixo ou de dar uma destinação mais adequada a ele, claramente uma abordagem instrumental, mas aos significados presentes nos sujeitos que desenvolvem ou não tais práticas, individual e coletivamente. Ou seja, extrair do ato objetivo as nuances subjetivas e intersubjetivas que o justificam e atuar sobre elas, sobre o universo invisível.

Tal busca de significados pode partir do ato em si e dele questionar quais são os operadores ideológicos e culturais que nos "obrigam" a agir como agimos (TASSARA; ARDANS, 2005) e que acabam por ofuscar nossa própria identidade, nossas escolhas pessoais, nossas idiossincrasias. Como questiona Carlos Drummond de Andrade em seu poema "Eu, etiqueta", onde está o "eu" por trás de todas as imposições sociais que recebemos e reproduzimos?

Bauman (2003, 2005, 2008) aborda o processo de desintegração das identidades individuais nas sociedades ocidentais por conta de um amálgama de fatores que se relacionam, retroalimentam e perpetuam: as novas noções de tempo provenientes das novas tecnologias; a transferência, do Estado para os indivíduos, da responsabilidade pela segurança das suas vidas; a participação do consumo na construção de identidades transitórias etc. Há alguma relação entre lixo, reciclagem e esses fatores? Compreende-se aqui que sim e deduz-se que, portanto, a questão da identidade é fundamental nos processos de educação ambiental que buscam a sustentabilidade das suas práticas (ALVES et al., 2010).

Entretanto, como destaca Mariotti (2000) em seu texto introdutório ao abordar fala de John Donne, no século XVII, "Nenhum homem é uma ilha", não basta o olhar "para dentro" promovido pela questão da identidade individual, já que tais identidades são forjadas no seio de uma sociedade, na relação com o Outro, na intersubjetividade.

Da mesma forma, os problemas "da vida" não desaparecerão se aqueles que consideramos "ambientais" forem sanados. O individualismo, a competição, a "correria do dia a dia" que não permite introspecção, a insegurança do trabalho e da renda, o sedentarismo, a pobreza, a injustiça, a exploração do outro, a dessacralização do mundo, as obsessões em relação ao corpo, entre outros, são também sintomas de um conjunto de valores que precisam ser adicionados a esse cadinho que busca produzir culturas que sejam mais sustentáveis em todas as multidimensões da vida - individual, social e ambiental. Todas essas são questões que afetam coletividades e não serão sanadas a partir de ações no âmbito privado. Trata-se de questões centrais no debate sobre "sustentabilidade" que vão muito além do alcance das práticas objetivas. No entanto, não podem ficar de fora dos processos educativos. 
A abordagem da dimensão de comunidade se faz ainda mais necessária em um país como o Brasil, de democracia recente e frágil (FREY, 2000). Há um risco real de que a ênfase de ações educativas sobre a resolução de problemas privados concretos (achar que a implantação de um programa de coleta seletiva é tudo o que tem a ser feito pela EA em uma escola, por exemplo) aliene educadores e educandos da participação pública para a construção de políticas que lidem com esses problemas "no atacado", visando às raízes dos problemas, e não aos seus sintomas. Outro exemplo atual dessa alienação seria a limitação de uma ação educativa às técnicas de plantio de árvores no pátio ou na calçada da escola enquanto no Congresso Nacional promove-se um processo de desmantelamento da legislação florestal brasileira, permitindo-se a perda de milhares de hectares de florestas. Ações privadas são necessárias, porém limitadas. É necessário um esforço para que esses desejos (e direitos) individuais e coletivos de educadores e educadoras ambientais (por exemplo, o de viver em um ambiente bem arborizado), que desencadeiam suas iniciativas nas suas imediações privadas, transcendam seus muros e sejam levados para disputar os afazeres do Estado na forma de políticas públicas (ANDRADE; SORRENTINO, 2013).

Isso justifica, mais uma vez, a importância de se inserir nos processos educativos a noção de comunidade. O conceito de comunidade remete a um ambiente ideal no qual seus habitantes compartilham um senso de segurança e coesão. Vai além da delimitação geográfica para carregar a percepção de pertencimento (BAUMAN, 2003), que tem sido perdida diante do crescimento das cidades e do avanço das tecnologias da comunicação, que aceleram os processos de globalização, reduzem o tempo e impõem tendências, desconsiderando os anseios locais. Tudo isso colabora para a dissolução de relacionamentos e para o desenraizamento de homens e mulheres. Se, por um lado, tal "autonomia" pode ser celebrada pelo mundo produtivo (BAUMAN, 2008), por outro, produz efeitos colaterais que estão se tornando regra nas sociedades atuais e sendo somatizados nos corpos e nas mentes, como a sensação de solidão e a depressão (COSTA, 2004).

Ninguém, entretanto, submete-se a processos de desenraizamento sem a clara percepção de compensações e de vantagens objetivas. E elas são oferecidas pelo consumo. Como aborda Costa (2004, p. 163), o consumo se tornou importante na "gestação, manutenção e reprodução de nossos ideais de eu", quando deixou de ser uma demanda individual e de sobrevivência e passou a ser uma exigência cultural (BAUMAN, 2008).

Aos poucos, a moral dos sentimentos, residente no universo psicológico, que enseja a nutrição e o cuidado duradouros, foi encontrando uma concorrente cada vez mais forte, a moral das sensações, com morada no corpo físico. Essa última lida com, como o próprio nome diz, sensações, que são fugazes e que precisam, assim, de alimentação constante (COSTA, 2004). E ninguém melhor que o consumo para oferecer sensações prazerosas constantes, na visão do consumo.

Para o autor, existe uma redefinição dos ideais de felicidade, agora ligados à satisfação de prazeres corpóreos instantâneos, ao narcisismo e ao hedonismo. Tal redefinição é perpetuada pela moral do "parecer", que hoje sobrepuja a do "ser" e também a do "ter". Essa é a leitura que Costa (2004) faz da "sociedade do espetáculo" que vivemos atualmente, na qual o que sobra para o indivíduo comum, o "invisível midiático" (p. 231), é se apegar a um "corpo-espetacular" (p. 232) na ilusão de pertencer a um mundo que não é seu e se esgotar no entretenimento, que "monopoliza a participação social e habitua o indivíduo a se eximir de pensar eticamente sobre o que acontece" (p. 232). Costa (2004) lista algumas consequências que têm se tornado comuns em seu consultório de psicanálise: dependências e adições (a drogas em geral, jogos, sexo, amor, consumo, exercícios físicos etc.); desregulações (anorexia, bulimia, síndrome do pânico, fobias...); inibições (os inibidos pelo mundo); estresse e deformações (os que ficaram para trás na busca pelo corpo perfeito).

Como visto, tudo isso faz parte do universo com o qual a educação ambiental deve lidar. Assim, em um mundo marcado pela superficialidade e transitoriedade das identidades individuais e coletivas (BAUMAN, 2003), a EA propõe a constituição de comunidades interpretativas e de 
aprendizagem (BRASIL, 2006), que são espaços com o objetivo de fortalecer a participação e a solidariedade entre os sujeitos que compartilham uma realidade a partir das histórias, espaços e tempos locais. Nessas comunidades a pluralidade encontrada é incentivada, tendo-se como certas sua incompletude e a importância do outro para que o aprendizado ocorra. É a disponibilidade para que possamos nos ver a partir dos outros (BOHM, 1999). Nas comunidades interpretativas visa-se também à repolitização e à radicalização da dimensão democrática da vida por meio da reinserção de homens e mulheres, em desvendamento, no mundo em que vivem (SANTOS, 2007).

As comunidades interpretativas, para ocorrerem de fato, devem ser permeadas pelo diálogo. Diálogo não como considerado pelo senso comum, mas o tipo de conversa que ocorre quando não há obstáculos postos entre os participantes, sem os papéis sociais, as agendas ou intenções escondidas, mas entre as essências de seres capazes de reconhecer suas exclusividades, entre sujeitos, o diálogo Eu-Tu (BUBER, 1979). Portanto, o diálogo fundamental é horizontal (FREIRE, 1987; YANKELOVICH, 2001), reflexivo (BOHM, 2005) e respeitoso (ISAACS, 1999). Ele se dá na presença, "no instante atual e plenamente presente" (BUBER, 1979, p. 14) e na disponibilidade recíproca entre Eu e Tu. Assim, no diálogo não há vencedores ou perdedores (BOHM, 2005; ISAACS, 1999), manipulação, convencimento ou indução (BUBER, 1979). Ocorre no "fluxo de significados" (dia = através; logo= palavra) (BOHM, 2005) entre os participantes e na emergência de algo novo, inexistente anteriormente (ISAACS, 1999).

Obviamente, a emergência do diálogo em uma prática coletiva depende de diferentes fatores, que devem ser construídos para que a conversa possa se dar em um ambiente continuamente seguro para o florescimento da diversidade em sua plenitude, de modo que a lida com os obstáculos e as contradições que aparecerão retroalimente o diálogo no grupo. Entretanto, como mostram Andrade, Luca e Sorrentino (2012), o diálogo, diferentemente do que é geralmente assumido, não busca o consenso ou a harmonia do grupo nem quer justificar as brutais desigualdades sociais encontradas com base na "forma preferida de viver" (BAUMAN, 2003, p. 98) de cada comunidade. $\mathrm{Na}$ verdade, o diálogo propõe o reconhecimento e a compreensão das diferenças, de suas implicações e da necessidade de convivência a despeito delas.

Portanto, um mergulho nas identidades individuais e coletivas, a busca pelo senso e pela prática comunitária e uma abordagem crítica dos ideais de felicidade, feitos coletivamente e permeados pelo diálogo, são alguns dos desafios colocados diante das comunidades interpretativas de aprendizagem, que aprendem fazendo e participando.

A formação das comunidades interpretativas visa, também, ao aumento da potência de agir dos indivíduos e do coletivo. Por meio da promoção de "bons encontros" (aqueles provenientes da alegria, que geram fortalecimento emocional e intelectual dos participantes do grupo e alimentam suas autoestimas), as comunidades interpretativas estimulam influências mútuas que levam à conscientização sobre as suas situações de vida, capacidades e talentos e fazem emergir uma característica imanente do humano, que é a vontade de participar individual e coletivamente para transformar a realidade na direção que deseja (SANTOS; COSTA-PINTO, 2005).

Como se vê, existe um universo subjetivo e intersubjetivo invisível incorporado às ações objetivas e concretas, e é em tal meio que residem muitas das questões e respostas para os processos educadores ambientalistas. É necessário atingir esse universo por meio das práticas pedagógicas, que devem extrapolar a objetividade.

\section{Conclusão}

O mundo que existe vai muito além do mundo que conseguimos perceber com nossos sentidos. Mesmo este, o verificável, só se torna compreensível por meio de um observador que o codifica e o decodifica a partir de princípios de organização que podem operar de forma 
consciente ou inconsciente. Isso descortina um novo e ilimitado universo que busca compreender como as pessoas em suas diversidades atribuem significados ao mundo e agem dentro dele.

Para a educação ambiental, essa diferença de percepção é fundamental. O foco teórico na realidade "objetiva" privada tende a produzir práticas que lidam com apenas uma dimensão da vida, a verificável, a concentrar as atenções na resolução técnica de problemas e a alienar educadores e educandos quanto a sua participação na esfera pública. Assim, apesar de a lida com as questões ambientais objetivas (o lixo, a poluição, o desmatamento etc.) ser importante na construção de sociedades cujos modos de vida sejam mais sustentáveis do que atualmente, ela não é suficiente. Um mundo limpo e florestado não necessariamente significa um mundo mais justo e democrático. A capacidade dos educandos de reconhecer e recolher embalagens no pátio de uma escola não os habilita a refletir sobre questões ligadas ao consumismo, à saúde, ou mesmo sobre políticas de resíduos sólidos. Por fim, pessoas que sabem a cor certa do recipiente para colocar uma embalagem reciclável plástica não são, da mesma forma, mais críticas, participativas e conscientes das razões de seus afetos e da presença do seu "eu" no mundo. É preciso ir além.

Compreender a realidade de uma maneira mais complexa significa, de outra forma, considerar um universo invisível, subjetivo e intersubjetivo, também multidimensional, porém existente e influenciador do mundo que vivenciamos. Significa também elaborar novas questões que busquem os sentidos e as conexões escondidos no "objetivo".

Este texto oferece a sugestão da entrada nos universos subjetivo e intersubjetivo por meio de cinco conceitos: identidade, comunidade, felicidade, diálogo e potência de agir, cujo aprofundamento é oferecido em Alves et al. (2010). Entende-se aqui que eles permitem, ao mesmo tempo, a organização e a compreensão de alguns dos porquês da vida e a extração de seus aspectos pedagógicos importantes que possam contribuir para a sustentabilidade dos processos de educação ambiental que são desenvolvidos em escolas e outros espaços educadores.

\section{Referências}

ALVES, Denise M. G. et al. Em busca da sustentabilidade educadora ambientalista. Ambientalmente sustentable, v. 1, n. 9-10, p. 7-34, 2010.

ANDRADE, Daniel Fonseca de.; LUCA, Andréa Quirino de; SORRENTINO, Marcos. O diálogo em processos de políticas públicas de educação ambiental no Brasil. Educação \& Sociedade, v. 33, n. 119, p. 613-630, abr./jun. 2012.

ANDRADE, Daniel Fonseca de; SORRENTINO, Marcos. Aproximando educadores ambientais de políticas públicas. In: SORRENTINO, Marcos et al. Educação ambiental e políticas públicas: conceitos, fundamentos e vivências. Curitiba: Appris, 2013. p. 215-223.

BAGNOLO, Carolina Messora. Encontros e desencontros das empresas e escolas no território da educação ambiental. 2012. 202 f. Tese (Doutorado em Educação) - Faculdade de Educação, Universidade Estadual de Campinas, Campinas, 2012. Disponível em: < http://www.bibliotecadigital.unicamp.br/document/?code $=000866055 \& \mathrm{fd}=\mathrm{y}>$. Acesso em: 11 out. 2012.

BAUMAN, Zygmunt. Comunidade: a busca por segurança no mundo atual. Rio de Janeiro: Zahar, 2003.

Identidade. Rio de Janeiro: Zahar, 2005. 
2008.

Vida para o consumo: a transformação das pessoas em mercadoria. Rio de Janeiro: Zahar,

BOHM, David. Wholeness and the implicate order. London, New York: Routledge, 1995.

. Unfolding meaning: a weekend of dialogue. London, New York: Routledge, 1999.

Diálogo: comunicação e redes de convivência. São Paulo: Palas Athena, 2005.

BRASIL. Programa Nacional de Formação de Educadoras(es) ambientais: por um Brasil educado e educando ambientalmente para a sustentabilidade. Brasília: Órgão Gestor da Política Nacional de Educação Ambiental, 2006. (Série Documentos Técnicos, n. 8).

BUBER, Martin. Eu e Tu. 2. ed. São Paulo: Cortez, Moraes, 1979.

CAMBI, Franco. História da pedagogia. São Paulo: Unesp, 1999.

CAPRA, Fritjof. O ponto de mutação: a ciência, a sociedade e a cultura emergente. 22. ed. São Paulo: Cultrix, 1999.

COSTA, Jurandir Freire. O vestígio e a aura: corpo e consumismo na moral do espetáculo. Rio de Janeiro: Garamond, 2004.

DESCARTES, René. $O$ discurso do método. Disponível em: $<$ www.fae.edu/pdf/biblioteca/O\%20Discurso\%20do\%20metodo.pdf $>$. Acesso em: 09 jun. 2010.

FELIX, Rozeli Aparecida Zanon. Coleta seletiva em ambiente escolar. Revista Eletrônica do Mestrado em Educação Ambiental, v. 18, jan./jun. 2007.

FREIRE, Paulo. Pedagogia do oprimido. 26. ed. Rio de Janeiro: Paz e Terra, 1987.

FREY, K. Políticas públicas: um debate conceitual e reflexões referentes à prática da análise de políticas públicas no Brasil. Planejamento e políticas públicas, n. 21, p. 211-259, jun. 2000.

GREIG, Sue; PIKE, Graham; SELBY, David. Greenprints for changing schools. London: WWF/Kogan Page, 1989.

HABERMAS, Jürgen. The theory of communicative action: reason and rationalization of society. Cambridge: Polity press, 1995.

ISAACS, William N. Dialogue and the art of thinking together: a pioneering approach to communicating in business and in life. New York: Doubleday, 1999.

MARIOTTI, Humberto. Complexidade e pensamento complexo. In: . As Paixões do Ego: Complexidade, Política e Solidariedade. São Paulo: Palas Athena, 2000. Disponível em: < http://www.teoriadacomplexidade.com.br/textos/teoriadacomplexidade/Complexidade-ePensamentoComplexo.pdf>. Acesso em: 09 jun. 2010.

MINAYO, Maria Cecilia de Souza. O desafio do conhecimento: pesquisa qualitativa em saúde. 11. ed. São Paulo: Hucitec, 2008. 
MORIN, Edgar. Ciência com consciência. 5. ed. Rio de Janeiro: Bertrand Brasil, 2001.

La epistemología de la complejidad. In: GARRIDO, Francisco; GONZÁLEZ DE MOLINA, Manuel; SERRANO, José Luis; SOLANA, José Luis (Ed.). El paradigma ecológico en las ciencias sociales. Barcelona: Icaria, 2007. p. 55-81.

NASCIMENTO, Izabela Rios do. Recolhimento de embalagens pela indústria através de um programa de educação ambiental: estudo de caso. In: CONGRESSO NACIONAL DE EXCELÊNCIA EM GESTÃO: energia, inovação, tecnologia e complexidade para a gestão sustentável, 6., 2010, Niterói. Anais... Niterói: 2010. p. 1-20. Disponível em: $<$ http://www.excelenciaemgestao.org/Portals/2/documents/

cneg6/anais/T10_0239_1108.pdf>. Acesso em: 10 out. 2012.

NICOLESCU, Basarab. O manifesto da transdisciplinaridade. São Paulo: Triom, 1999.

SANTOS, Boaventura de Sousa. A crítica da razão indolente: contra o desperdício da experiência. 6. ed. São Paulo: Cortez, 2007.

SANTOS, Cláudia Coelho; COSTA-PINTO, Alessandra Buonavoglia. Potência de ação. In: FERRARO JÚNIOR, Luiz Antonio (Org.). Encontros e Caminhos: formação de educadoras(es) ambientais e coletivos educadores. Brasília: MMA/DEA, 2005. p. 297-302.

TACHIZAWA, Takeshy. Gestão ambiental e responsabilidade social corporativa: estratégias de negócios focadas na realidade brasileira. 5. ed. São Paulo: Atlas, 2008.

TASSARA, Eda Terezinha de Oliveira; ARDANS, Omar. Intervenção psicossocial: desvendando o sujeito histórico e desvelando os fundamentos da educação ambiental critica. In: FERRARO JÚNIOR, Luiz Antonio (Org.). Encontros e caminhos: formação de educadoras(es) ambientais e coletivos educadores. Brasília: MMA/DEA, 2005. p. 203-216.

YANKELOVICH, Daniel. The magic of dialogue: transforming conflict into cooperation. New York: Touchstone, 2001.

Artigo recebido em 07/10/2011

Artigo aprovado em 05/11/2012 